\title{
Symptomatic Solitary Gastric Diverticulum: A Rare Endoscopic Finding
}

\section{Divertículo Gástrico Solitário Sintomático: Achado Endoscópico Inusual}

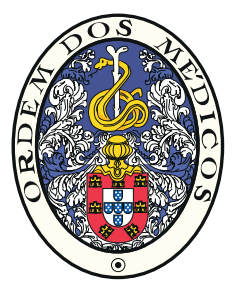

\author{
Marta GRAVITO-SOARES $₫{ }^{* 1}$, Elisa GRAVITO-SOARES ${ }^{* 1}$, Luis TOMÉ 1,2 \\ Acta Med Port 2018 Oct;31(10):597-597 - https://doi.org/10.20344/amp.9760
}

Keywords: Abdominal Pain; Diverticulum, Stomach/diagnosis

Palavras-chave: Divertículo Gástrico/diagnóstico; Dor Abdominal

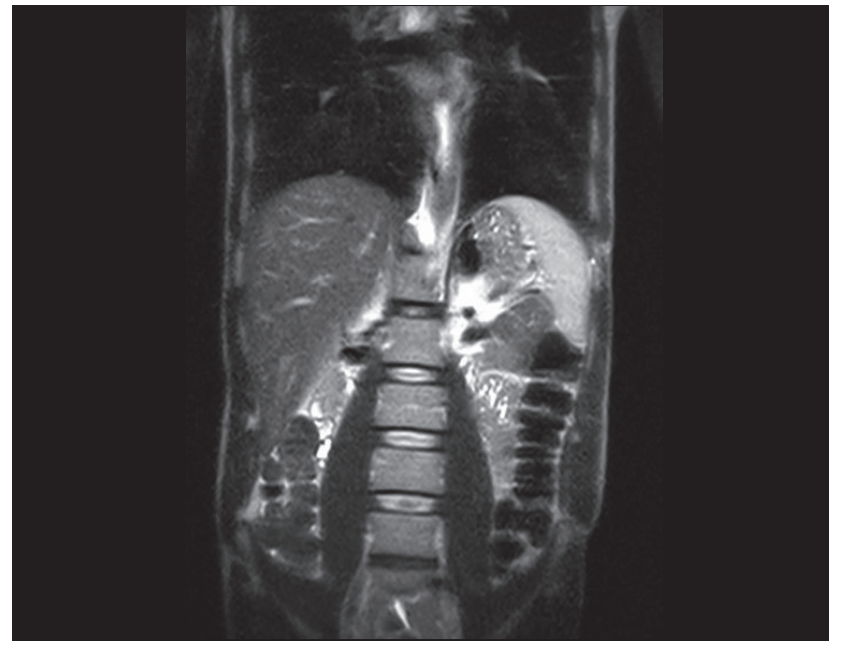

Figure 1 - Abdominal and pelvic magnetic resonance imaging detecting a mass in the left paravertebral region behind the stomach showing an air-fluid level measuring $37 \mathrm{~mm} \times 18 \mathrm{~mm}$

The authors report the case of a 54-years-old man with chronic hepatitis C successfully treated with ledipasvir/ sofosbuvir. An abdominal ultrasonography was performed because of nonspecific upper abdominal pain and showed three uncharacterized liver nodules. Subsequently, an abdominopelvic magnetic resonance was done and revealed four liver hemangiomas (16 $\mathrm{mm}$ maximum diameter in $\mathrm{S} 2 /$ S3). Additionally, a $37 \mathrm{~mm} \times 18 \mathrm{~mm}$ mass in the left paravertebral region behind the stomach showing an air-fluid level was also observed (Fig. 1). An esophagogastroduodenoscopy was then performed showing a single food-free diverticulum in the gastric fundus (Fig. 2). The patient had

\section{PROTECTION OF HUMANS AND ANIMALS}

The authors declare that the procedures were followed according to the regulations established by the Clinical Research and Ethics Committee and to the Helsinki Declaration of the World Medical Association. DATA CONFIDENTIALITY

The authors declare having followed the protocols in use at their working center regarding patients' data publication.

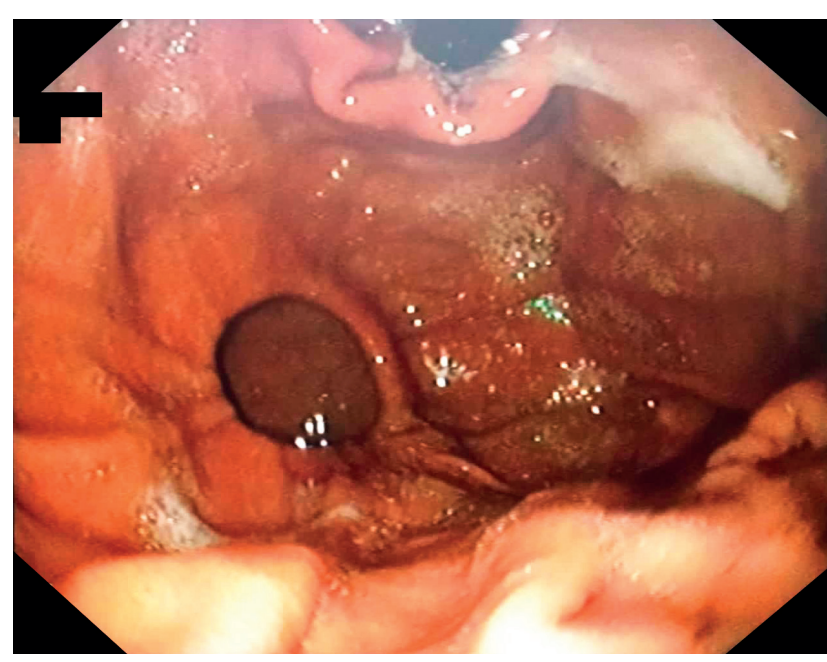

Figure 2 - Endoscopic appearance of the solitary fundal gastric diverticulum measuring $36 \mathrm{~mm} \times 20 \mathrm{~mm}$ and without food content

abdominal discomfort during the endoscopic examination by blowing the diverticulum with air. He became asymptomatic after one month of proton-pump inhibitors (PPI) and irritant free diet with low intake of acidic, spicy, highly salted or high-fat foods, without symptomatic relapse after a twoyear follow-up.

The stomach is a very rare location of diverticular disease $^{1-3}$ with endoscopic incidence ranging from $0.01 \%$ to $0.11 \% .^{1-4}$ In rare cases, diverticula can be symptomatic, usually improving with PPI. ${ }^{1}$ Surgical treatment is indicated for patients with large/complicated diverticula or who have failed medical therapy. ${ }^{1-4}$

\section{PATIENT CONSENT \\ Obtained.}

CONFLICTS OF INTEREST

All authors report no conflict of interest.

\section{FUNDING SOURCES}

This research received no specific grant from any funding agency in the public, commercial, or not-for-profit sectors.

\section{REFERENCES}

1. Rashid F, Aber A, Iftikhar SY. A review on gastric diverticulum. World J Emerg Surg. 2012;7:1

2. Hajini FF, Husain M, Bhat A, Bukhari SI. Gastric diverticulum a rare endoscopic finding. BMJ Case Rep. 2014;2014

3. Kumar P, Chandra K. A case of gastric diverticulum (Solitary fundal diverticulum) - Pictorial CME. Indian J Clin Practice. 2014;25:360-1.

4. Jeyarajah DR, Dunbar KB. Diverticula of the pharynx, esophagus, stomach, and small intestine. In: Feldman M, Friedman LS, Brandt LJ, editors. Sleisenger and Fordtran's gastrointestinal and liver disease: pathophysiology/diagnosis/management. $10^{\text {th }}$ ed. Philadelphia: Elsevier Saunders; 2016. p. 402-3.

${ }^{*}$ Authors contributed equally for this work.

1. Gastroenterology Department. Centro Hospitalar e Universitário de Coimbra. Coimbra. Portugal.

2. Faculty of Medicine. University of Coimbra. Coimbra. Portugal.

$\bowtie$ Autor correspondente: Marta Gravito-Soares.ms18498@gmail.com

Recebido: 05 de outubro de 2017 - Aceite: 15 de maio de 2018| Copyright @ Ordem dos Médicos 2018 